\title{
A IDENTIDADE AMAZÔNICA NAS JOIAS PARAENSES
}

\author{
Amanda Gatinho Teixeira
}

\begin{abstract}
Mestra em Antropologia pela Universidade Federal do Pará. Especialista em Design, Computação Gráfica e Multimídia pelo Instituto de Estudos Superiores da Amazônia. Possui graduação em Artes pela Universidade Federal do Pará. E-mail: agteixeira10@gmail.com
\end{abstract}

\section{RESUMO}

O trabalho aborda a joalheria paraense produzida e comercializada no Polo Joalheiro em Belém-PA. Desde a sua criação, em 1998, o Programa Polo Joalheiro procurou apropriar-se da narrativa poética amazônica operando como suporte material e estético sobre os designers que criam joias baseadas em valores pertencentes à cultura local, traduzindo assim a identidade amazônica através de: costumes, lendas, mitos, fauna, flora, festividades folclóricas e religiosas. Para tal entendimento, abordo as questões da construção da identidade dos sujeitos pós-modernos, a fim de compreender as especificidades da chamada identidade amazônica.

PALAVRAS-CHAVE: Joias Paraenses. Polo Joalheiro. Identidade Amazônica.

\section{AMAZONIAN IDENTITY IN PARÁ JEWELS}

\begin{abstract}
The work deals with paraense jewelery produced and sold at the Joalheiro Pole in Belém-PA. Since its creation in 1998, the Polo Joalheiro Program has sought to appropriate the Amazonian poetic narrative by operating as material and aesthetic support for designers who create jewelry based on values belonging to local culture, thus translating the Amazonian identity through: customs, legends, myths, fauna, flora, folk and religious festivities. For this understanding, I address the issues of the construction of the identity of postmodern subjects, in order to understand the specificities of the so-called Amazonian identity.
\end{abstract}

KEYWORDS: Paraenses Jewels. Jeweler Polo. Amazonian Identity. 


\section{O PROGRAMA POLO JOALHEIRO}

Para compreendermos o Programa Polo Joalheiro na cidade de Belém, se faz necessário um breve contexto histórico do processo de exploração de metais e gemas no estado do Pará.

Na década de 1980, impulsionado pela extração de ouro dos garimpos locais, originouse um alto crescimento do setor joalheiro do município de Itaituba, no Pará. Entretanto, este setor não possuía uma organização formal, o que refletia diretamente na qualidade dos produtos, pois as joias costumeiramente eram cópias de catálogos e revistas.

A partir da década de 1990, a produção dos garimpos enfraqueceu devido à escassez do minério que era extraído por métodos manuais. Assim, o setor mineral passou a ser cada vez mais dominado por grandes empresas e por processos mecânicos, o que gerou muitos desempregos. Em meados de 1996, a Secretaria Municipal do Meio Ambiente de Itaituba promoveu o cadastramento dos ourives da cidade, a fim de reverter a baixa qualificação técnica na qual trabalhavam esses profissionais, bem como, promover um maior volume de produção.

Esta ação resultou na criação da AJOI em outubro de 1997, que posteriormente originou a COOPERJAM que possuía como objetivo criar uma força econômica para aumentar a qualificação da mão-de-obra local e facilitar o incentivo para competir no mercado. Essas ações foram transferidas de Itaituba para Belém, devido o maior peso político da capital paraense. Assim, no ano de 1998, o governo do Pará liderado por Almir Gabriel, criou o Programa de Desenvolvimento do Setor de Gemas e Joias do Estado do Pará, designado Polo Joalheiro do Pará, com a finalidade de possibilitar o maior escoamento desta produção e funcionar como uma espécie de vitrine para o Programa recém-criado, no ano de 2002, surge o Espaço São José Liberto (ESJL) que abriga o Polo Joalheiro.

O prédio que abriga o ESJL é originário do século XVIII, ocasião em que era denominado Convento São José. Posteriormente, funcionou como depósito de pólvora, quartel, olaria e hospital, mas certamente o que povoa a memória de grande parte dos paraenses é o espaço como presídio. Assim, em uma tentativa de conceder uma nova e inspiradora importância ao lugar, o espaço ganhou outro nome em sua composição, tornando-se Espaço São José Liberto, fazendo uma clara alusão à liberdade. Como principal diferencial dos produtos produzidos e comercializados no ESJL, o Programa procurou apropriar-se da narrativa poética do imaginário cultural amazônico para criar coleções de joias, com ênfase na agregação de valor ao produto. 


\section{$21^{a}$ COLEÇÃO JOIAS DO PARÁ-AMAZÔNIA-BRASIL}

Para uma maior visibilidade das joias que seriam produzidas no início do Programa, foram ofertados cursos e oficinas aos agentes da cadeia produtiva. Além do desenvolvimento do design e do emprego de novos materiais nas joias, houve a necessidade de novos insumos de produção, tanto no que se refere à matéria-prima quanto ao maquinário utilizado, acarretando mudanças em toda a cadeia produtiva.

Dessa forma, em 1999, foi realizada a $1^{\text {a }}$ Oficina de Design de Joias, a qual foi coordenada pela consultoria da Associação dos Joalheiros e Relojoeiros do Estado do Rio de Janeiro (AJORIO) e pelo Instituto Brasileiro de Gemas e Metais (IBGM), reunindo artistas plásticos, arquitetos, ourives e artesãos para a criação da $1^{\circ}$ Coleção Joias do Pará-AmazôniaBrasil (Fig.01), configurando em um marco inicial do Programa Polo Joalheiro.

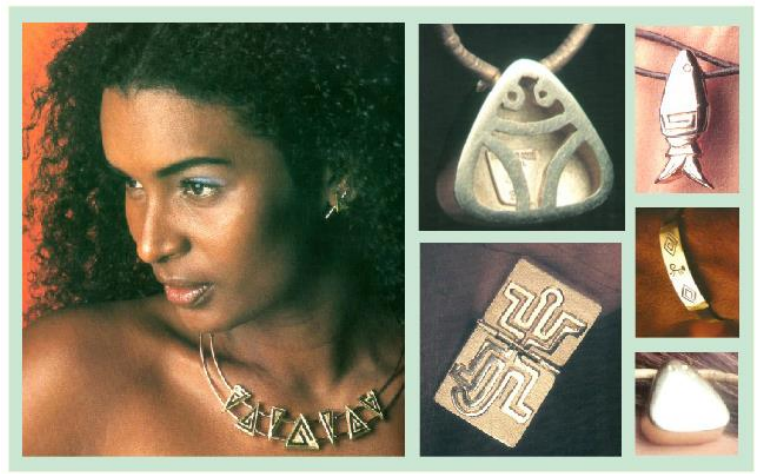

Fig. 01: Peças da $1^{\mathrm{a}}$ Coleção de Joias do Pará Fonte: Seteps, 2002.

Nela, podemos observar o repertório da cultura amazônica, através de peças que represem lendas e mitos, a fauna, bem como, os grafismos rupestres e indígenas, ocorrendo assim, a valorização de elementos simbólicos locais e também do imaginário popular. Outro ponto que merece destaque é que a joia paraense é classificada como um objeto artesanal, concebida a partir da sabedoria dos mestres ourives.

Assim, neste contexto, a joia paraense já nasce no cenário contemporâneo procurando combinar tendências tradicionais e vanguardistas em sua materialização. É importante salientar que as joias contemporâneas permitem o processo de experimentação não apenas de formas mais inusitadas mas, sobretudo, pelo trabalho com outros tipos de materiais não convencionais, os chamados materiais alternativos. Então, não é de se estranhar que estas joias mesclam em sua composição metais nobres aliados ao plástico, tecido, couro, madeira, fibras naturais, sementes, entre outros múltiplos materiais. 
Dessa forma, o Programa Polo Joalheiro apropriou-se bem dessas características que são tão aclamadas nas joias contemporâneas, elegendo seu próprio contexto social como um vasto universo de ideias e referências

\section{A CULTURA POPULAR AMAZÔNICA COMO SUPORTE POÉTICO E ESTÉTICO NAS JOIAS}

Desde o início do Programa Polo Joalheiro o desenvolvimento das ações se dá em três grandes vertentes: a capacitação e a inovação tecnológica; promoção e comercialização e o funcionamento do território do ESJL. Que para a diretora do ESJL, Rosa Helena Neves ${ }^{1}$, a ideia da complementaridade entre arquitetura, o design, a história, o patrimônio histórico, a cultura, o turismo, a economia criativa, são os fatores que contribuem no fortalecimento das joias com as características do Programa (Fig.02).

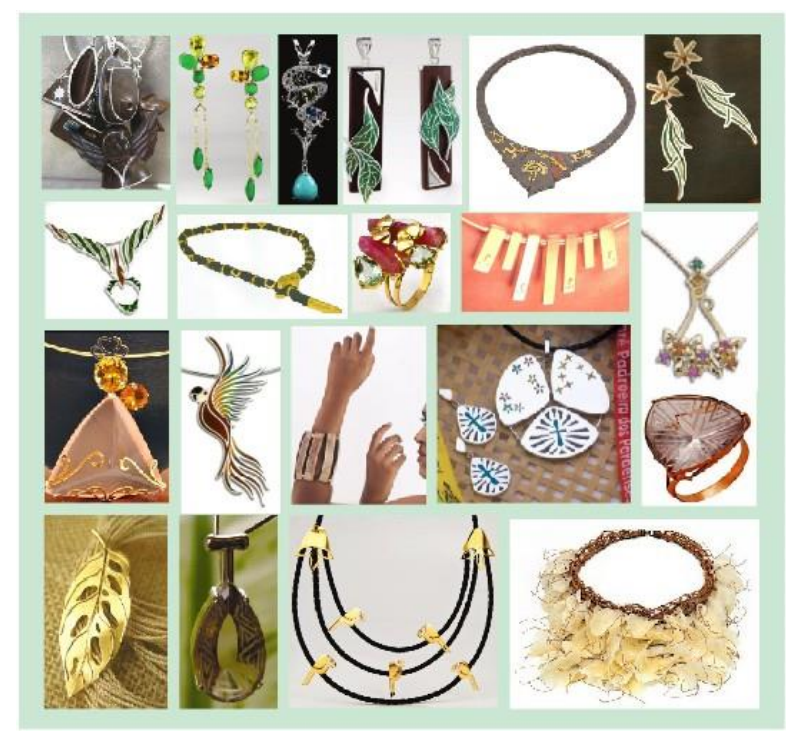

Figura 02: Joias produzidas no Programa Polo Joalheiro Fonte: Catálogos institucionais do Programa

Assim, a representação da santa Senhora de Nazaré e o seu manto, os ícones do Círio de Nazaré2 representado pelos ex-votos, o desenho de flores e folhas encontradas na região, o

\footnotetext{
${ }^{1}$ Entrevista realizada em 22 de setembro de 2015. Possui graduação em Pedagogia e mestrado em Políticas Públicas pela Universidade Federa do Pará. Atualmente é diretora do Instituto de Gemas e Joias da Amazônia e do Espaço São José Liberto.

${ }^{2}$ Procissão católica que ocorre anualmente na cidade de Belém, no segundo domingo do mês de outubro. Esta festividade é considerada uma das maiores celebrações religiosas do mundo. Foi tombada em 2000 pelo Instituto do Patrimônio Histórico e Artístico Nacional (IPHAN), como patrimônio imaterial da cultura brasileira e em 2013 foi declarado Patrimônio Cultural Imaterial da Humanidade. Disponível em: http://portal.iphan.gov.br/pagina/detalhes/55 
grafismo indígena, os desenhos rupestres, a fruta proveniente das mangueiras - uma das árvores mais comuns encontradas nas ruas de Belém, a iconografia da lenda da cobra grande, os pássaros, a menção ao remo - lapidado com a iconografia marajoara - usado pelos ribeirinhos e o muiraquitã ${ }^{3}$ estilizado são alguns dos exemplos encontrados nestas joias produzidas pelo Programa.

Neste sentido, podemos afirmar que ao longo da existência do Programa Polo Joalheiro, a cultura popular amazônica opera como suporte poético e estético sobre os designers que criam joias baseadas em suas memórias imagéticas e/ou visuais, agregando significados e valores pertencentes à cultura local, materializando a identidade regional através de: conceitos, história, costumes, lendas, mitos, inserção de elementos culturais como fauna, flora, festividades folclóricas e religiosas.

Desse modo, observamos que o discurso oficial do Polo Joalheiro é constituído sob a imagem de uma Amazônia idealizada, no qual a perene e exclusiva herança regional e indígena geralmente se mostra materializada por meio de sua estética, o que fica evidenciado no pensamento de Paes Loureiro (2004, p. 3$)^{4}$.

O que caracteriza a cultura amazônica é a dominante poética do seu imaginário. É natural, portanto, que essa poética se torne pregnante no design de joias do Pará. Uma produção criativa de objetos cuja originalidade decorre dessa atmosfera eco-mítico-lendária, que alimenta culturalmente os seus artesãos profissionais, tribalizados na aldeia pós-moderna do projeto do Polo Joalheiro. Representando o contemporâneo revalorizador da tradição, essas joias tem depurado no seu design a universalidade que lhes é estratégia fundamental, a partir de especificidades paraense-amazônicas que lhes são essenciais.

É nesse momento que observamos a preocupação do designer de joias paraense em agregar valores pertencentes à cultura local, traduzindo assim, a chamada identidade cultural ${ }^{5}$ regional amazônica. Sob essa ótica, o Programa Polo Joalheiro orienta o que deve ser produzido pelos joalheiros, sem haver desvios nos objetivos de valorização da biodiversidade

${ }^{3} \mathrm{O}$ vocábulo vem do tupi, mas há divergências sobre sua origem e seu objetivo. Os objetos já foram considerados vestígios de antigas culturas asiáticas, peças esculpidas pelas Amazonas, mulheres guerreiras, ou ainda distintivos usados por caciques ou chefes, como amuletos de boa sorte (GUIA DO MUSEU DE GEMAS - JOIAS E ARTESANATOS DO PARÁ, 2004, p.12).

${ }^{4}$ Texto de apresentação do catálogo Pará Expojoia 2004.

${ }^{5}$ Para Denys Cuche (1999, p. 177), o conceito de identidade cultural remete à questão da identidade social de um indivíduo que é caracterizada pelo conjunto de suas vinculações em um sistema social. $\mathrm{O}$ autor aponta ainda que todo o grupo é dotado de uma identidade que corresponde à sua definição social, dessa forma a identidade social ao mesmo tempo que é inclusiva, ao identificar membros do grupo que são idênticos sob um determinado ponto de vista, também é excludente, ao distinguir um grupo dos outros grupos. Neste sentido, o Programa Polo Joalheiro procura enfatizar em seus participantes o sentimento de vinculação e pertencimento à região amazônica, para desta forma trabalhar uma espécie de identidade coletiva a fim de ser projetada no produto joia e consequentemente, serem comercializadas. 
e cultura local, neste sentido:

Do total de peças produzidas por cada joalheiro ou produtor, $70 \%$ deve ser com inspiração amazônica e mão-de-obra local, isso compreende fauna, flora, lendas, costumes, manifestações culturais, tudo que pertence à região, toda sua biodiversidade e, os $30 \%$ restante, podem ser a partir de temática universal (utilização de referenciais de criação inspirados em todo o mundo), porém também com mão-de-obra local. A definição de percentuais cria no produtor, uma prática de incentivo e valorização da sua própria identidade fortalecendo com isso, as diretrizes estabelecidas no início do Programa (NUNES, 2013, p.43).

Outro ponto significativo presente nas joias do Programa Polo Joalheiro são as diversas representações simbólicas ${ }^{6}$ de Nossa Senhora de Nazaré, santa que possui grande prestígio entre a população paraense. Tais representações surgem das mais figurativas às mais abstratas (Fig.03), assim, a presença da imagem da santa sempre surge como temática, seja por uma convenção social ou ainda por serem induzidos a criar joias com este tema, tendo como principal suporte o workshop anual do evento "Joias de Nazaré"7.

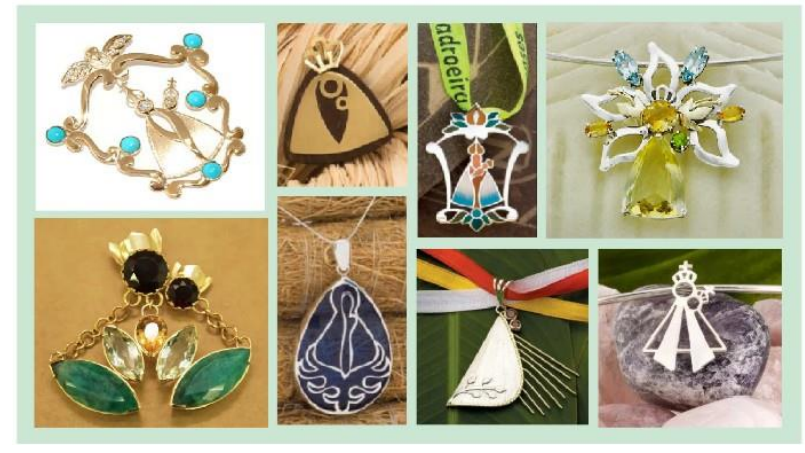

Fig. 03: Representações de Nossa Senhora de Nazaré

Fonte: Catálogos institucionais do Programa

Relação que fica evidenciado no pensamento de Rodrigues (2012, p. 3) ao afirmar que a sociedade e/ou grupo constrói e reproduz a sua identidade através do apego ao seu passado, mitológico, histórico e, principalmente, simbólico-religioso.

[...] o fator religião desempenha um papel muito importante no processo de construção identitária; o sistema religioso, na lógica funcionalista [...] é um dos principais meios de construção de solidariedades e de representações identitárias. [...] toda a religião, todo o universo simbólico-religioso, implica uma mobilização específica da memória coletiva e de sua transmissão e reprodução social.

Dessa forma, a religião e seus desdobramentos formam um sistema de fortes referências

\footnotetext{
${ }^{6}$ Símbolo é o signo que representa seu objeto independente de sua semelhança (ícone) ou das suas relações causais (índice), e sim por referências abstratas em virtude da associação de idéias produzidas por convenção ou pacto coletivo (MORAES, 2009, p.1). Disponível em: http://www.virginiamoraes.com

${ }^{7}$ Exposição realizada anualmente no Polo Joalheiro que possui como principal objetivo materializar nas joias diversos significados referentes ao Círio de Nazaré.
} 
que os atores sociais recorrem a fim de refletir sobre o universo onde estão submersos.

Outra temática que costumeiramente está presente nas coleções das joias do Programa Polo Joalheiro é a representação do açai ${ }^{8}$, fruta muita apreciada pelo povo amazônico (Fig.4), o qual está presente desde a $1^{\mathrm{a}}$ Coleção desenvolvida no ESJL.

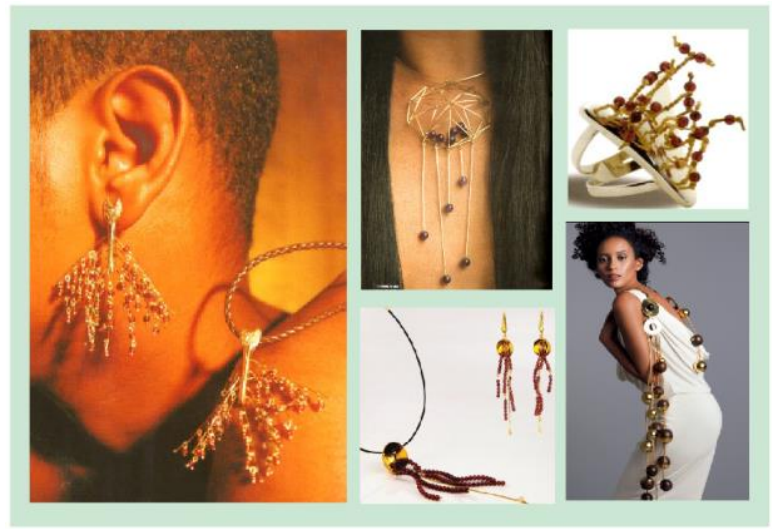

Fig. 04: Representações do açaí nas joias Fonte: Arquivo de pesquisa, 2015.

Ao observamos a figura acima, apontamos que a representação do açaí é trabalhada tanto na forma mimética/figurativa, como o conjunto de brincos e colar que ilustra o cacho da fruta, tal como é encontrado nas palmeiras; quanto conceitualmente, como o colar que pesa mais de meio kilo, que simula os caroços do fruto, em grandes bolas e círculos vazados ou preenchidos, os quais foram confeccionados em ouro, madeira, caroço de tucumã e fibra de arumã, desenhado por Selma Montenegro.

No que concerne à identidade amazônica, Fabio Castro (2011, p. 12) a observa como um processo de invenção do e no presente, portanto ela não se faz herdeira de um passado e nem se configura na recuperação de uma essência, que é extremamente difundida, assim como a Amazônia é considerada um espaço híbrido e múltiplo, e não somente uma região.

A concepção das joias paraenses vai além do caráter ornamental, comum a todos os adornos, mas também pode ser configurada em algumas peças, como mímese dos elementos

${ }^{8}$ Euterpe oleraceae Martius é uma palmeira que alcança em torno de 15 a $20 \mathrm{~m}$ de altura e 12 a $18 \mathrm{~cm}$ de diâmetro. É uma planta que prefere os terrenos alagados e áreas úmidas, por isso sua ocorrência é mais frequente às margens dos rios. É encontrada principalmente na região Norte do Brasil, nos Estados do Pará, Amazonas, Maranhão e Amapá, e estende-se para as Guianas e Venezuela. Dela são extraídos o palmito e o fruto para o consumo alimentar.

Seu fruto é popularmente conhecido como açaí, é arredondado e pesa cerca de dois gramas. Somente $17 \%$ dele são comestíveis (polpa com casca), sendo necessários cerca de $2 \mathrm{~kg}$ de frutos para produzir um litro de suco. $\mathrm{O}$ restante representa o caroço, contendo a semente oleaginosa. A cor do fruto maduro é púrpura a quase preta. Disponível em: http://sban.cloudpainel.com.br/files/revistas_publicacoes/334.pdf 
presentes na natureza, estejam eles presentes no mundo real ou imagético. Ao longo da existência do Programa Polo Joalheiro, observo a notória evolução das joias paraenses, sobretudo no design e no acabamento das peças. Nos primeiros anos, a maioria das joias possuíam um desenho mais figurativo, assemelhando-se às representações das formas reais que eram vistas na natureza. Com o passar dos anos, analiso que as joias recebem desenhos mais estilizados e complexos em suas formas compositivas, mas sempre procurando evidenciar a identidade cultural amazônica.

Ainda sobre a discussão das identidades culturais, agora no contexto dos estudos culturais latino-americanos, cito o pensamento de Jesús Martín-Barbero que entende a identidade como uma representação da diferença que está ligada ao mercado. "A identidade local é assim levada a se transformar em uma representação da diferença que se possa fazê-la comercializável, ou seja, submetida ao turbilhão das colagens e hibridações que impõe o mercado" (MARTÍN-BARBERO, 2004, p. 268). Assim, o autor considera um caráter de hibridação e colagem para as identidades evocando a vivência aberta das identidades culturais.

Ao observarmos as criações dos designers integrantes do Programa Polo Joalheiro, fica evidenciado a estética local regional em seus repertórios compositivos que pode ou não ser ressignificada. Porém, é valido assinalar que as joias que circulam no Espaço São José Liberto também sofrem processos de contaminação/hibridização por outras zonas de contato a partir da relação dinâmica do povo paraense com outros grupos étnicos que passaram a habitar esta região, sejam elas a joalheria européia clássica (aqui representada principalmente pelas joias comercializadas na loja Belém da Saudade), as joias que remontam as religiões de matriz africana (comercializadas na loja Una), as joias com grafismos étnicos (comercializadas pelo colombiano Argemiro Muñoz em sua loja Joiartmiro), entre outros exemplares.

Por meio da construção de símbolos materializados nas joias paraenses, estas representam uma das diversas estratégias do processo identitário da construção e consequente valoração das raízes locais, as quais são pautadas na constituição da territorialidade paraense, semiografando nosso território cultural. 


\section{REFERÊNCIAS BIBLIOGRÁFICAS}

BALDI, M.; CASTRO, R. B. de. A inovação no Polo Joalheiro de Belém: uma análise a partir do mecanismo de imersão estrutural. Cadernos EBAPE.BR [online], Rio de Janeiro, n.3, pp. 492-513, 2010.

CUCHE, D. A noção de cultura nas ciências sociais. São Paulo: EDUSC, 1999.

CASTRO, F. F. de. Entre o mito e a fronteira. Belém: Labor Editoral, 2011.

GUIA DO MUSEU DE GEMAS E JOIAS E ARTESANATO DO PARÁ. Belém: Associação São José, 2004.
MARTÍN-BARBERO, J. Ofício de cartógrafo: travessias latinoamericanas de comunicação na cultura. São Paulo: Loyola, 2004.

NUNES, J. T. de B. Elementos da biodiversidade Amazônica no pensar-fazer de joalheiros de Belém: a vivência como educação. Dissertação de Mestrado. Programa de Pós-Graduação em Educação da Universidade do Estado do Pará, 2013.

PAES LOUREIRO, J. de J. As jóias reais do imaginário, in Catálogo de jóias do Pará Coleção Agosto 2004. Belém: Associação São José Liberto, 2004.

TEIXEIRA. A, G. A Identidade Amazônica Nas Joias Paraenses. Complexitas - Rev. Fil. Tem. Belém, v. 4, n. $1, \quad$ p. 9-17, jan./jun. 2019. Disponível em: http://www.periodicos.ufpa.br/index.php/complexitas/article/view/8037>. Acesso em: 30 de janeiro de 2020. 